\title{
Laboreal
}

Volume $3 \mathrm{~N}^{\circ} 1$ | 2007

Varia

\section{Erro, autonomia e gestão individual e colectiva da produção}

Error, autonomía y gestión individual y colectiva de la producción

Erreur, autonomie et gestion individuelle et collective de la production

Error, autonomy and individual and collective management of production

\section{Catarina Silva}

\section{(2) OpenEdition}

Journals

Edição electrónica

URL: http://journals.openedition.org/laboreal/12892

DOI: $10.4000 /$ laboreal. 12892

ISSN: 1646-5237

\section{Editora}

Universidade do Porto

Refêrencia eletrónica

Catarina Silva, "Erro, autonomia e gestão individual e colectiva da produção », Laboreal [Online], Volume $3 \mathrm{~N}^{0} 1$ | 2007, posto online no dia 01 julho 2007, consultado o 24 setembro 2020. URL : http:// journals.openedition.org/laboreal/12892 ; DOl : https://doi.org/10.4000/laboreal.12892

Este documento foi criado de forma automática no dia 24 setembro 2020.

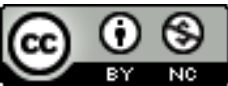

Laboreal está licenciado com uma Licença Creative Commons - Atribuição-NãoComercial 4.0 Internacional. 


\title{
Erro, autonomia e gestão individual e colectiva da produção
}

\author{
Error, autonomía y gestión individual y colectiva de la producción \\ Erreur, autonomie et gestion individuelle et collective de la production \\ Error, autonomy and individual and collective management of production
}

\section{Catarina Silva}

\section{REFERÊNCIA}

Silva, C. (2006). Erro, autonomia e gestão individual e colectiva da produção : interrogar as práticas orgnizacionais de prevenção do erro. Tese de Doutoramento, Universidade Técnica de Lisboa, Lisboa.

\section{NOTA DO EDITOR}

Manuscrito recebido em : Março/2007

Aceite após peritagem em : Junho/2007

\section{Ponto de partida}

1 Situamos o ponto de partida deste trabalho nas reflexões suscitadas pelos resultados obtidos na investigação realizada (Silva \& Lacomblez, 1998), alguns anos antes, numa indústria de montagem de cablagens para veículos onde quantificámos a ocorrência, a detecção e a recuperação do erro pelas próprias operadoras.

2 O estudo que agora apresentamos foi realizado numa empresa que se dedica à montagem, entre outros produtos, de auto-rádios para a indústria automóvel, laborando em três horários consecutivos com equipas fixas. 
3 A análise preliminar da organização e actividade de trabalho mostrou-nos que no contexto de montagem de auto-rádios as operadoras não estavam implicadas na gestão da qualidade nos mesmos moldes que observámos na montagem de cablagens, devido quer à implementação de sistemas de detecção de erro nos postos de trabalho existentes na linha de montagem, quer à adopção de regras explícitas, separando, por equipas distintas, a actividade de montagem da de reparação.

Assim, assumimos como objectivo da investigação analisar as consequências das opções de organização do trabalho sobre o erro numa linha de montagem final de auto-rádios, recorrendo a uma abordagem longitudinal retrospectiva da ocorrência de erro.

Procurámos compreender, quer o alcance da concepção do controlo de qualidade, que não afasta a ocorrência do erro, mas inibe a gestão do erro em tempo real pelas operadoras de montagem final, quer o papel das dinâmicas de regulação do processo de trabalho, individuais e colectivas, indispensáveis à gestão da produção, sob o efeito de uma organização que consideramos discricionária,

6 Do ponto de vista teórico, apoiámo-nos nos trabalhos de Maggi (2003); de Terssac $(1992 ; 2002)$ de Terssac e Dubois (1992) e de Reynaud $(1999,2004)$, os quais nos permitiram uma interpretação da actividade de trabalho considerando as mudanças organizacionais que hoje se impõem ao modelo taylorista-fordista.

\section{Uma organização pós-fordista}

7 Que "nova" organização do trabalho estava então em causa? Tentámos respostas a questões que espelham as trajectórias de mudança do modelo clássico "Scientific Management" (taylorista-fordista) e que se impõem, hoje, aos sistemas produtivos : (1) Como é gerida a incerteza dos pedidos dos clientes? (2) Como se processa as relações cliente-fornecedor no interior da empresa? (3) Como é alcançada a redução dos prazos comerciais ? (4) Como é gerida a enorme variedade dos produtos? (5) Como é feito e coordenado o controlo quantitativo e qualitativo da produção?

Constamos estar na presença de uma organização do trabalho dita pós-fordista, pois exerce igualmente a racionalização do trabalho, mas assente, de acordo com Maggi, Terssac e Dubois, em espaços de aç̧ão discricionários, ou seja, que solicita dos actores iniciativa, inovação, responsabilidade, decisão e reconhece (pelo menos em parte) as suas competências, mas num quadro de dependência determinado superiormente.

O uso da discrição - e não cedência de autonomia, dado que esta supõe independência dos sujeitos na condução dos processos de acção torna-se imprescindível para assegurar a produção em condições de incerteza permanente.

\section{A regulação do processo de trabalho}

10 A regulação é um processo central para as organizações que privilegiam a discrição como modo de fazer face à incerteza com que se confrontam permanentemente. Este pressuposto levounos a analisar a actividade de trabalho de montagem de autorádios, procurando respostas às questões: (1) Quais as obrigações implícitas numa tarefa discricionária? (2) Que actividade, individual e colectiva responde a uma tarefa desta natureza ? (3) Que processo de regulação social impõe este tipo de tarefa? 
11 Duas evidências emergiram. Do ponto de vista conceptual julgamos ter mostrado a proficuidade para a ergonomia de mobilizar para a sua leitura do real de trabalho outras quadros teóricos, neste caso concreto, da sociologia do trabalho protagonizada por Terssac e Reynaud. Ao introduzirmos na nossa análise os diferentes sistemas de regras que coabitam e se combinam nos processos de trabalho, conseguimos ultrapassar a visão "taylorista" da ergonomia de confrontar a tarefa (regras de controlo) com a actividade (regras autónomas) e fazer emergir os processos de regulação conjunta (regras efectivas). Do ponto de vista empírico, os dados mostraramnos o quão complexa é a regulação do processo de trabalho, tanto do ponto de vista individual como colectivo; como essa regulação assentava inevitavelmente em iniciativas, em tomadas pontuais de "autonomia", para fazer face aos constrangimentos que quotidianamente se atravessam no processo de trabalho ; enfim, como a regulação tinha subjacente processos de negociação, nem sempre claramente explícitos, entre diferentes estruturas decisionais - vertical ou horizontal mas absolutamente essenciais para o alcance dos objectivos da empresa.

\section{Produção, erro e organização do trabalho}

\subsection{Cronologia de acontecimentos}

12 O conhecimento do funcionamento do sistema produtivo levounos a questionar a eficácia das opções de organização do trabalho na ocorrência de erro. Sendo-nos apenas possível obter dados retrospectivos de erro (registos arquivados provenientes da estação de reparação), decidimos pesquisar os acontecimentos ocorridos na linha de montagem relativos : (1) ao modo de gestão dos recursos humanos (mobilidade); (2) às variações do planeamento da produção (volume e diversidade) ; (3) à transição entre produtos (descontinuados e novos); (4) às alterações do processo de montagem (estruturais e funcionais), tendo em vista elaborar uma cronologia que nos ajudasse a interpretar os resultados do tratamento dos dados do erro, considerando o conhecimento adquirido sobre a situação de trabalho. Dezoito meses constituíram o nosso período de análise retrospectiva.

\subsection{0 que nos dizem os erros?}

Do tratamento dos nossos dados, o erro manifestou-se como uma das consequências de opções de gestão de recursos humanos baseada em critérios, essencialmente, económicos e comerciais. Acreditamos que melhores resultados seriam obtidos se houvesse uma aposta efectiva na estabilização (e não na mobilidade) dos recursos humanos - em concreto do terceiro horário (da noite) e um reconhecimento do lugar do saber-fazer, para além da mera execução de operações de montagem. Vimos o quanto a mobilidade dos recursos humanos pode comprometer a construção da representação comum, essencial quando o apelo ao colectivo é mais veemente aumento do volume de produção, transições entre produtos, disfuncionamentos dos equipamentos da linha etc. - viabilizando maiores fracassos. A racionalização dos recursos humanos, praticada com o objectivo de alcançar ganhos económicos, acarreta custos acrescidos na produção, derivados dos erros humanos. 
14 Verificámos que apesar de uma concepção da organização do trabalho visando a prevenção e a detecção precoce do erro, o erro continuava a ocorrer. As lacunas desta concepção eram superadas pela dinâmica colectiva de gestão da actividade, que vimos ser praticada pela equipa do primeiro horário, pois permitia um melhor controlo do tempo, logo da produção e dos seus resultados, em termos de erro. Nesta linha de montagem, a não imposição de uma cadência tinha subjacente a possibilidade de fazer uso discricionário do tempo, com o objectivo de alcançar a produção, e não de humanizar o trabalho.

15 Constatámos, também, que a gestão da variabilidade de produção e logo do erro saiu beneficiada pelas transformações que foram sendo introduzidas na disposição da estrutura física da linha de montagem.

16 A análise detalhada dos procedimentos empregues revelou redefinições visando a fiabilidade do produto. Observámos a prática de operações suplementares de prevenção, com êxito, a determinados aspectos do produto, para os quais não existia outro meio de controlo. Constatámos, como a realização de pequenas reparações (clandestinas!), acabavam por ser objecto de negociação com a hierarquia : troca-se o reconhecimento da competência para fazer recuperações pela garantia de cumprir o planeamento. Confirmámos o envolvimento das operadoras na gestão do erro, apesar de não estar contemplado na organização formal.

17 Presenciámos como a acção colectiva vai também no sentido de procurar a regulação da carga de trabalho no seio da equipa, de promover a construção da competência individual, mas também, colectiva, de facilitar a gestão das situações críticas de trabalho, bem como de prevenir conflitos, etc. Por isso, podemos afirmar que o erro estava também no centro de processos de regulação social.

\section{Concepção preventiva do erro ou aprender com o quotidiano?}

Este trabalho incita a repensar se a aposta deve ser efectivamente no sentido de uma concepção preventiva dos erros ou se devemos aprender com as práticas do quotidiano. Vimos como esta concepção preventiva do erro esquece: 1) as competências, as iniciativas, muitas vezes individuais mas cujo resultado se reflecte no trabalho dos outros ; e 2) que o erro é, também, objecto de negociação social e um meio ao serviço da fiabilidade. Pareceu-nos estar perante uma gestão do erro deixada na deriva da organização informal do trabalho. Mais do que concentrar esforços a procurar nos espaços, que acabam por ficar à responsabilidade e iniciativa dos operadores, onde ele errou, o que violou, parece-nos mais interessante ver como, nesse mesmo espaço, a gestão informal do erro e da produção acaba por emergir. Trata-se, pois, de olhar a construção de regras próprias de acção, que não se devem confundir, neste contexto, com uma verdadeira autonomia, mas antes considerar-se como conquistas pontuais implicitamente negociadas, no seio dos colectivos e com a sua hierarquia. Esta gestão informal ao confundirse com a actividade de trabalho corrente, exige-nos um olhar atento. É também preciso ultrapassar as interpretações dos próprios operadores que desvalorizam essas iniciativas individuais, não as reconhecendo como sinais fundamentais da sua competência. A análise das actividades de trabalho, mais do que focalizar-se nos acontecimentos excepcionais, deve pois considerar as práticas do 
quotidiano. Deste ponto de vista será interessante reter a perspectiva da teoria do agir organizacional (Maggi, 2003) que opta por falar em ajustamentos contínuos, necessários e inevitáveis durante o desenrolar do processo de acção em vez de erro.

Realçamos o interesse e a necessidade de repensar formulas organizacionais que reconheçam essas práticas do quotidiano como verdadeiras actividades profissionais, abrindo caminho a uma abordagem que dará, certamente, maior visibilidade à participação activa dos operadores na gestão do seu processo de trabalho.

\section{BIBLIOGRAFIA}

Terssac, G. de (1992). Autonomie dans le travail. Paris : PUF.

Terssac, G. de \& Dubois, P. (Eds.). (1992). Les nouvelles rationalisations de la production. Toulouse : Cépadues Editions.

Terssac, G. de (Ed.). (2002). Le travail : une aventure collective. Toulouse : Editions Octares.

Maggi, B. (2003). De l'agir organisationnel. Un point de vue sur le travail, le bien-être, l'apprentissage. Toulouse : Octares Editions.

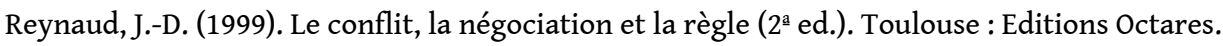

Reynaud, J.-D. (2004). Les règles du jeu. L'action collective et la régulation sociale. Paris : Armand Colin.

Silva, C. \& Lacomblez (1998). Quand le contrôle de la qualité vient, toute contrainte de temps étant égale par ailleurs : l'erreur humaine dans le montage de câbles électriques pour véhicules. Paper presented at the XXXIIICongresso da SELF “ Temps et travail », Paris, Setembro, 16-18.

\section{AUTOR}

\section{CATARINA SILVA}

Faculdade de Motricidade Humana Estrada da Costa, Dafundo, 1495 - 688 Lisboa Portugal csilva@fmh.utl.pt 